\title{
Investigation of Ergonomics Risk Factors for Musculoskeletal Disorders among Oil Palm Workers using Quick Exposure Check (QEC)
}

\author{
Sukadarin, E.H. ${ }^{1, a}$, Deros, B.M. ${ }^{1, b}$, Ghani, J.A. ${ }^{1, c}$, Ismail, A.R. ${ }^{2, d}$, \\ Mokhtar, M.M ${ }^{1, \mathrm{e}}$ and Mohamad, $\mathrm{D}^{1, \mathrm{f}}$. \\ ${ }^{1}$ Department of Mechanical and Materials Engineering, \\ Faculty of Engineering and Built Environment, \\ Universiti Kebangsaan Malaysia, \\ 43600 Bangi, Selangor, Malaysia \\ ${ }^{2}$ Faculty of Mechanical Engineering \\ Universiti Malaysia Pahang \\ 26600 Pekan, Pahang Darul Makmur, Malaysia \\ aezrinhani@gmail.com, ’hjbaba@eng.ukm.my, 'jaharah@eng.ukm.my , 'arasdan@gmail.com , \\ emaznon@siswa.ukm.edu.my, darliana_mohamad@yahoo.com
}

Keywords: postural analysis, QEC system, oil palm fruit harvesters

\begin{abstract}
Oil palm workers perform daily activities that exposed themselves to various ergonomics risk factors. To harvest oil palm fruits from tall trees, specific technique is required. To quantify the ergonomics risks factors, postural analysis was conducted using Quick Exposure Check (QEC) system. It was found oil palm workers were exposed to many postural problems while performing harvesting and collecting fresh fruit bunch (FFB) activities. However, to quantify the actual load, many limitations of the QEC have been revealed such the missing of legs assessment, the crude analysis for arm and shoulder, no pushing and pulling assessment and the biased may be existed due to the workers' perception on the ergonomics factors. Thus, it can be concluded that QEC system was not suitable for conducting postural analysis during harvesting in oil palm plantation especially in tall trees due to the above limitations.
\end{abstract}

\section{Introduction}

Oil palm workers are exposed to ergonomics problems in their routine works. The ergonomics problems, which are unavoidable, such as: awkward posture, repetitive movements, weight handling, forces in pushing and pulling activities. Without carefully management of the problems, each worker has a high tendency to suffer from musculoskeletal problems [1]. In a small plantation, transporting fresh fruit bunch (FFB) from oil palm trees is done manually. Mechanized equipment can hardly be seen because the small plantation owner could not afford to buy the equipment due to its high price. So, most of the hazardous works have to be performed manually by human. Due to that, workplace injury in oil palm plantation is common $[2,3]$.

Harvesting FFB and pruning fronds are the main activities during harvesting period. Usually the harvester use chisel or sickle to harvest the FFB. Chisel is used for short palms (less than $3 \mathrm{~m}$ high), while sickle is used for taller palms. A lot of energy is required and the harvester must be fit enough to ensure that the cutting process of FFB is successful regardless in short or tall palms [4].

Specifically in tall palms, manual cutting of FFB is tough. Harvesters need to pull long pole that holds the sickle so that the FFB is totally cut-off from the bunch stalk. A large force and very high sickle speed is required [5].That is why, harvesters must be skillful and fit to do it. FFB harvester in oil palm plantations performs many types of activities, which involved many different postures and movements.

Besides harvesting, collecting of FFB is another major activity in the oil palm plantation. In this specific case study, the workers collect FFB from ground into a mini truck, and then transfer 
FFB from the mini truck into a lorry. The manual activity demands a lot of efforts. More than one FFB are collected daily. The weight of one FFB is about $20 \mathrm{~kg}$. The risk for workers who involved with that activity to get MSDs is prominent [6].

Janowitz et al. [7] found that to identify and understand the physical load in any physical activities, can be done using posture analysis method. In this study, the authors had applied the Quick Exposure Check (QEC) system to understand the working postures issues faced by oil palm harvesters while harvest the FFB from tall trees.

\section{Quick Exposure Check (QEC)}

Quick Exposure Check (QEC) is a tool to measure musculoskeletal risk exposure. It was developed at the Robens Centre for Health Ergonomics in the United Kingdom by Li and Buckle [8] and enhanced for several times by $[8,9,10]$. The tool was tested in term of its validity and reliability in the original tool development. The testing process using simulated and workplace tasks $[11,12]$. Both intra-observer and inter-observer were found high in term of sensitivity and reliability [13]. It has also proven applicable to be used in wide range of working activities, easy to use with a pen-and-paper, the most importantly is that whenever QEC is implemented workers activities are uninterrupted $[14,15,12]$.

All the important elements in most of work systems that contribute to the occurrence of MSDs can be measured by using QEC [10]. In QEC, there are four main body areas (back, wrist/ arms, shoulder hand, neck) that can be assessed. The psychosocial factors evaluation is also included. The assessment also takes account movement (i.e. static/dynamic), frequency, subjective forces, weight handled, vibration and shift length into account. The special about QEC is that, it combines the observer's assessment with the worker's answers in a set of closed questions [15, 10 , 16] indirectly participatory ergonomics is involved [11]. Using QEC, tasks can normally be assessed within $10 \mathrm{~min}$. It is similar with many other observational methods, the QEC also has a scoring system, and exposure levels at the end of the assessment process.

\section{Methodology}

This study was conducted at an oil palm plantation located at Kuala Selangor. The respondents consist of 7 workers. Six workers were doing harvesting and 2 of them were also doing collecting of FFB. Meanwhile, 1 worker only focused on driving a mini truck. The respondents were asked to fill up the subjective evaluation form in order to evaluate their perceptions on their discomfort experienced. Then, the harvesters need to perform their working activities as usual. Although using QEC as a tool to assess working posture, only pen and paper are needed, harvesting FFB activities from tall trees were recorded using a video camera. This was done to ensure that the actual activities were captured so that the QEC assessment can be analyzed and reevaluated in the laboratory.

\section{Result and Discussion}

\section{Demographic}

The result of demographics data is presented in the (Table 1). The value of mean and standard deviation of respondents' age is 41.2 and 9.4 respectively. For level of education, 3 respondents studied up to the primary school level, 2 respondents studied up to lower secondary school and the other 2 respondents studied in upper secondary school. From the 7 respondents, 5 respondents are smokers and currently none of them are doing exercise frequently. 
Table 1 Demographic Data $(\mathrm{N}=7)$

\begin{tabular}{ll}
\hline Characteristics & $\mathrm{N}(\%)$ \\
\hline Age (mean \pm SD) yrs $=41.3 \pm 9.4$ & \\
Educational level & $3(42.8)$ \\
- Primary school & $2(28.6)$ \\
- Lower secondary school & $2(28.6)$ \\
- Upper secondary school & \\
Smoking Status & $5(71.4)$ \\
- Yes & $2(28.6)$ \\
- No & \\
- Years smoking (mean $\pm \mathrm{SD})$ yrs $=19.2 \pm 7.3$ & 0 \\
Exercise frequency & \\
\hline
\end{tabular}

Physical ergonomics factors

In the subjective evaluation form, physical ergonomics factors were included. The factors that have been considered are working experience, working days in a month, working hours in a day, break duration, number of FFB harvested in a day and time (in sec) to harvest each FFB. The value of mean and standard deviation of the physical ergonomics factors are presented in (Table 2). From the respondents' answer regarding physical ergonomics factors in their working activities, all respondents were experiencing work fatigue, with the proportion $71.4 \%$ experiencing sometimes and $28.6 \%$ frequently.

Table 2 Physical Ergonomic Factors (N=7)

\begin{tabular}{lcc}
\hline Characteristics & Mean (SD) & $\mathrm{N}(\%)$ \\
\hline Working experience (yrs) & $12.1(9.3)$ & - \\
Working days in a month (days) & $24.9(0.4)$ & - \\
Working hours in a day (hrs) & $6.0(1.2)$ & - \\
Break duration (minute) & $60.0(0.0)$ & - \\
Number of FFB harvested in a day & $88.6(3.8)$ & - \\
Time to harvest 1 FFB (sec) & $4.1(1.5)$ & - \\
Experiencing work fatigue & - & $7(100)$ \\
Frequency having work fatigue & & \\
- Sometimes & - & $5(71.4)$ \\
- Frequently & - & $2(28.6)$ \\
\hline
\end{tabular}

\section{Postures of oil palm workers in a small plantation}

Postures that involved during cutting FFB from tall trees can be seen in the following figures. In general, each harvester, is performs the same postures in order to cut the FFB or to prune the fronds from a tall palm. Bending of the knees, flexion and extension for back and neck are normal. Extreme force for hand and shoulder as can be seen in (Figure 1).

For collecting the cut FFB from the ground into a mini truck, only two workers were involved. To study and understand the postures involved in collecting FFB process from ground to mini truck, Figure 2 gives the best explanation. Figure 3 shows the actual scenario when the workers have to load FFB from the mini truck into the lorry. Loading FFB at this time was continuously done until the mini truck is it empty. Figure 4, shows the mini truck driver's working posture. Basically the driver performs the same postures throughout the working session.

\section{Postural Analysis using QEC}

To analyze postural loads of oil palm workers, the activities are grouped into 4 categories. There are harvesting, loading from ground to truck, loading from truck to lorry and driving truck. Each category consists of different numbers of worker. In order to quantify the postural load, each worker for each activity has been evaluated individually. After the assessment was completed, the scores were then averaged based on each category. To identify the exposure level of the studied risk factors, the obtained scores are compared with the guidelines as shown in Table 3. 

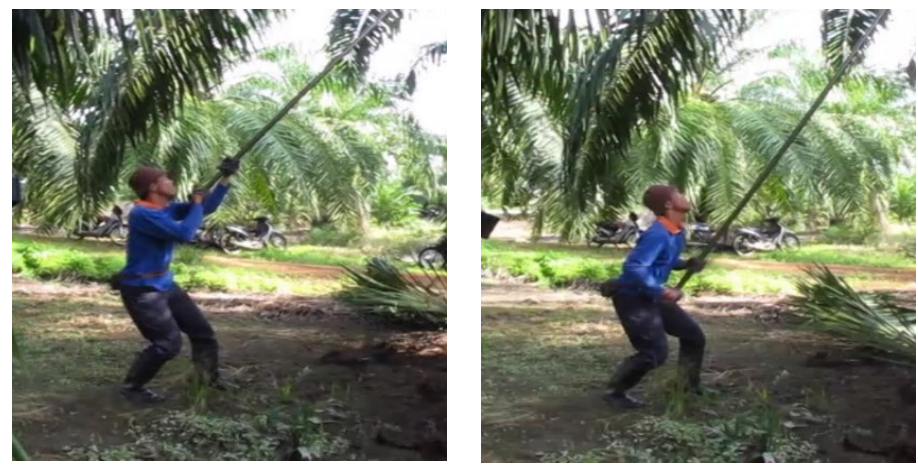

Figure 1 General postures during FFB harvesting activities

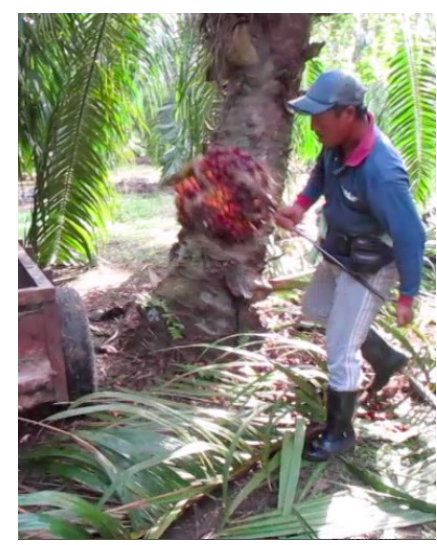

Figure 2 Workers posture performing FFB collecting activities

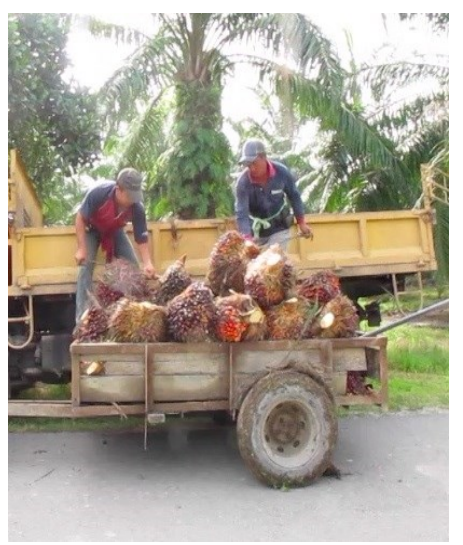

Figure 3 Workers posture during unloading FFB activities from mini truck into the lorry

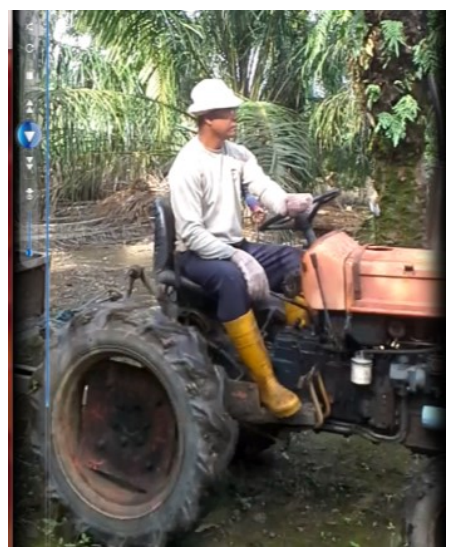

Figure 4 The truck driver's posture

Table 3 QEC Guideline for Scoring Exposure Levels

\begin{tabular}{lcccc}
\hline \multicolumn{5}{c}{ Exposure Levels for Body Regions } \\
\hline Score & Low & Moderate & High & Very High \\
Back (static) & $8-15$ & $16-22$ & $23-29$ & $29-40$ \\
Back (moving) & $10-20$ & $21-30$ & $31-40$ & $41-56$ \\
Shoulder / arm & $10-20$ & $21-30$ & $31-40$ & $41-56$ \\
Wrist / hand & $10-20$ & $21-30$ & $31-40$ & $41-46$ \\
Neck & $4-6$ & $8-10$ & $12-14$ & $16-18$ \\
\hline \multicolumn{4}{c}{ Exposure Levels for Environmental and Organizational Factors } \\
\hline Score & Low & Moderate & High & Very High \\
Driving & 1 & 4 & 9 & - \\
Vibration & 1 & 4 & 9 & - \\
Work Pace & 1 & 4 & 9 & - \\
Stress & 1 & 4 & 9 & 16 \\
\hline
\end{tabular}

In accordance with the exposure levels for body regions in Figure 5, the result shows the loading activity of FFB from ground to the truck was giving a high risk to the workers' back and shoulder/arm and moderate risk for wrist/hand. Loading of FBB from the truck to lorry leads to high risk to back and wrist / hand and moderate risk to shoulder/ arm. Meanwhile, for harvesting FFB the risk for back and wrist / hand only moderate and low risk for shoulder / arm and neck towards MSDs. QEC result also shows that driving in oil palm plantation is safe because the risk level are low for all body regions.

Exposure levels for environmental and organizational factors are shown in Figure 6. Only driving and vibration risk factor affect to driving activity in oil palm plantation with the moderate 
exposure level. For harvesting and loading activities in environmental and organizational factors the exposure levels are all low.

\begin{tabular}{|c|c|c|c|c|}
\hline & Harvesting & $\begin{array}{c}\text { Loading } \\
\text { (ground - truck) }\end{array}$ & $\begin{array}{c}\text { Loading } \\
\text { (truck - lorry) }\end{array}$ & Driving \\
\hline Back & $\sqrt{24}$ & 460 & 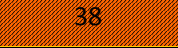 & 14 \\
\hline Shoulder / Arm & $\| \mathbb{1} 8$ & 44 & 28 & 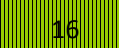 \\
\hline Wrist / Hand & 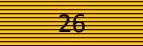 & 36 & 30 & $\| 16$ \\
\hline Neck & 6 & 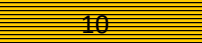 & 6 & 8 \\
\hline \multirow{2}{*}{ Color Indicator } & & & & \\
\hline & Low & Moderate & High & Very High \\
\hline
\end{tabular}

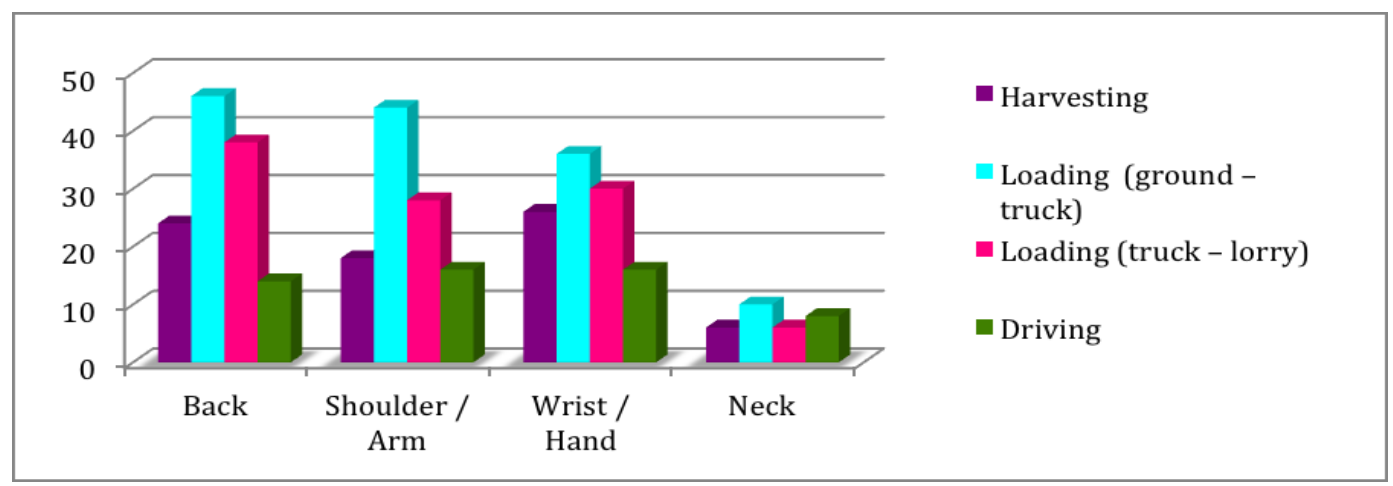

Figure 5 QEC Results for Exposure Levels for Body Regions

\begin{tabular}{|c|c|c|c|c|}
\hline & Harvesting & Loading (ground - truck) & Loading (truck - lorry) & Driving \\
\hline Driving & $\|$ A & 1 & (1) & 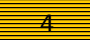 \\
\hline Vibration & (11). & $\| \mathbb{A}$ & $\|$ A & 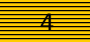 \\
\hline Work pace & $\|\mathbb{A}\|$ & $\|$ IIIII. & $\|$ iin.|. & $\mathbb{1} 1 \|$ \\
\hline Stress & $\mathbb{1} \mid \mathbb{\|}$ & $\|\mathbb{A}\|$ & $\|\mathbb{A}\|$ & $\mathbb{1} \mid \mathbb{1}$ \\
\hline Color Indicator & \multicolumn{2}{|c|}{ Low } & \multicolumn{2}{|c|}{ Moderate } \\
\hline
\end{tabular}

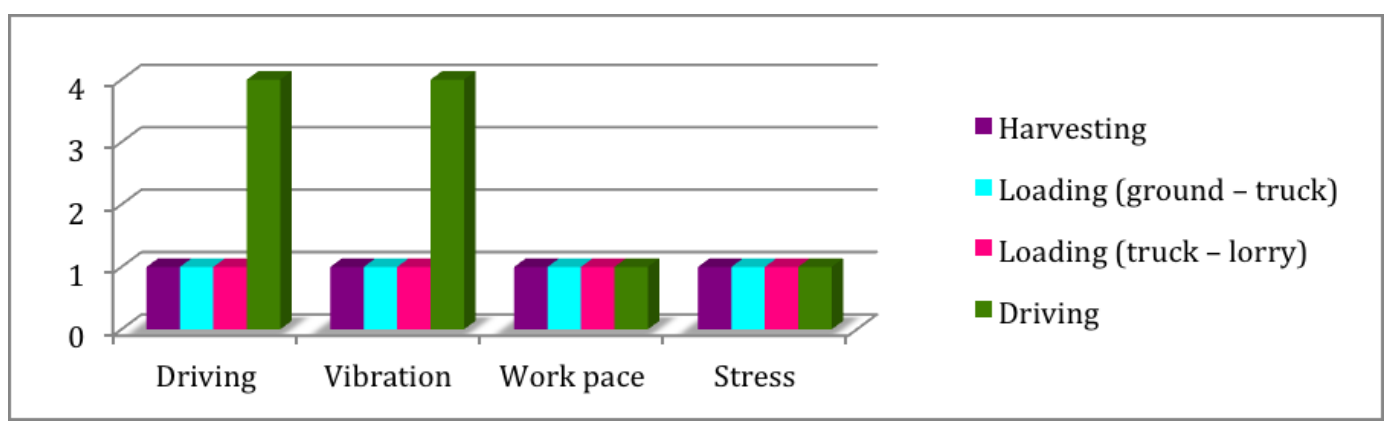

Figure 6 QEC Results of Exposure Levels for Environmental and Organizational Factors

The QEC system was proved to be applicable for assessing MSDs. The application of QEC system can be seen in a cross-sectional study among cardiologist population in Isfahan [18] and in a study among industrial workers in Iran [19]. The QEC system also has been studied and compared with other observational methods to test the effectiveness of the proposed intervention in a construction industry [11]. From all the published applications of QEC, the results produced were found to be beneficial. 
However, there are some limitations in QEC system in order to quantify the exact load in every activity among harvester. In harvesting of palm oil from tall trees, both limbs were actively involved to ensure that the harvesting process is perfectly done. Upper limbs are used to hold the heavy and long sickle, so that the sickle is positioned correctly in the cutting area. The lower limbs need to be strong enough to ensure that the body is in a stand position for a certain period of times. However in QEC, the analysis of lower limbs is still missing. There is no information on how to measure the legs condition during harvesting of palm oil in the QEC system. Meanwhile, for shoulder and arm assessment, by combining the assessment of the shoulder and arm factors in a single issue, some of the problematic postures can be neglected. It also makes the assessment of the shoulder too basic and thus failed to identify the real shoulder problems among harvesters.

The process to pull sickle quickly and repetitively in the harvesting activity until the FFB is cut is not easy. Surprisingly the study result shows that harvesting activity is not giving any harm to workers by looking at the level of exposure which is moderate and low. One reason is that, there is no measure to quantify the pulling risk factor in that activity. Although in QEC, the force elements have been taken into consideration, it just touched one factor which is weight of the load. Other factors that need human force, such as pushing and pulling have been neglected. For maximum force level exerted in the working activity, workers need to estimate the risk. However, to what extend the workers are educated enough about the risk of that are still questionable. That is why expert's opinion and judgment is a must to be included with workers perception as well towards force exertion in any observational ergonomics risk assessment. In addition to measure forceful exertion, the measurement cannot be done by estimation. Forceful exertion should have to be quantified with a special apparatus such as using Electromyography (EMG) system [20]. The same goes to the estimation of weight of objects that need to be determined by harvesters. The harvesters might done a mistake during estimating the weight. So the assessment will be inaccurate [17].

\section{Conclusion}

The ergonomics risk factors for WMDs were investigated using QEC system. The authors found that harvesters have been exposed to very high of WRMS risk at back (in dynamic condition) and at shoulder / arm for loading from ground to truck activity. High exposure level for wrist / and in loading (ground to truck), for loading (truck to lorry) affected body regions are back and wrist / hand. Meanwhile, for other factors the exposure levels are moderate and low. For environmental and organizational factors, the exposure levels are all low except for driving and vibrations are moderate for driving truck. Although the results found are beneficial as a preliminary study, the inadequacy of QEC system in certain important parameters might be could lead to the misinterpretation (i.e. for example, missing of legs assessment and too simple analysis of the shoulder and arm). In addition, the way on how inexperience harvesters have to estimate the weight of objects and the force that existed in harvesting activities is questionable due their limited knowledge in ergonomics. Other issues are the absence of a method to quantify pushing and pulling factors. With all the limitations, it can be concluded that QEC system might not be suitable for assessing the ergonomics risk factors for WRMDs in oil palm plantations especially in harvesting palm oil in tall trees

\section{Reference}

[1] N. Jaffar, A. H. Abdul-Tharim, I. F. Mohd-Kamar, N. S. Lop, A Literature Review of Ergonomics Risk Factors in Construction Industry, Procedia Engineering. 20 (2011) 89-97.

[2] J. C. Davies, G. J. Kemp, S. P. Frostick, C. E. Dickinson, Manual handling injuries and long term disability, Safety Science. 41 (2003) 611-625.

[3] V. V. Khanzode, J. Maiti, P. K. Ray, Occupational injury and accident research: A comprehensive review, Safety Science. 50 (5) (2012) 1355-1367. 
[4] A. R. Jelani, A. R. Shuib, A. Hitam, J. Jamak, M. M. Noor, Hand-held mechanical cutter, MPOB Infomation Series. 180 (2003) 1-2.

[5] A. R. Jelani, A. Hitam, J. Jamak, M. Noor, Y. Gono, O. Ariffin, Cantas TM - A tool for the efficient harvesting of oil palm fresh fruit bunches, Journal of Oil Palm Research. 20 (2008) 548-558.

[6] J. Yoon, A. Shiekhzadeh, M. Nordin, The effect of load weight vs. pace on muscle recruitment during lifting, Applied Ergonomics. 43(6) (2012) 1044-50.

[7] I. L. Janowitz, M. Gillen, G. Ryan, D. Rempel, L. Trupin, L. Swig, K. Mullen, R. Rugulies, P. D. Blanc, Measuring the physical demands of work in hospital settings: design and implementation of an ergonomics assessment, Applied Ergonomics. 37(5) (2006) 641-58.

[8] G. Li, P. Buckle, A practical method for the assessment of work-related musculoskeletal risks-Quick Exposure Check (QEC), Proceedings of the Human Factors and Ergonomics Society $42^{\text {nd }}$ Annual Meeting. 2 (1998) $1351-1355$.

[9] G. David, V. Woods, P. Buckle, D. Stubbs, Further development of the Quick Exposure Check (QEC), In: Ergonomics in the Digital Age. Proceedings of the XVth Triennial Congress of the International Ergonomics Association. (2003) 24-29, Seoul, Korea.

[10] G. David, V. Woods, G. Li, P. Buckle, The development of the Quick Exposure Check (QEC) for assessing exposure to risk factors for work-related musculoskeletal disorders, Applied Ergonomics. 39(1) (2008) 57-69.

[11] P. Simonsson , R. Rwamamara, Ergonomic exposures from the usage of conventional and self compacting concrete, Proceeding for the 17th Annual Conference of the International Group for Lean Construction. (2009) 313-322.

[12] E.-P. Takala, I. Pehkonen, M. Forsman, G.-Å. Hansson, S. E. Mathiassen, W. P. Neumann, G. Sjøgaard, K. B. Veiersted, R. H. Westgaard, J. Winkel, Systematic evaluation of observational methods assessing biomechanical exposures at work, Scandinavian Journal of Work, Environment \& Health. 36(1) (2010) 3-24.

[13] G. Li , P. Buckle, Current techniques for assessing physical exposure to work-related musculoskeletal risks, with emphasis on posture-based methods, Ergonomics. 42 (5) (1999) 674-695.

[14] A. Bell, An ergonomic analysis of vacuum cleaning tasks using observational risk assessment tools, University of Wollongong. (2008).

[15] M. Motamedzade, M. R. Ashuri, R. Golmohammadi, H. Mahjub, Comparison of ergonomic risk assessment outputs from rapid entire body assessment and quick exposure check in an engine oil company, Journal of Research in Health Sciences. 11(1) (2011).

[16] A. Bell, J. Steele, Risk of musculoskeletal injury among cleaners during vacuuming, Ergonomics. 55(2) (2012) 237-247.

[17] M.-E. Chiasson, D. Imbeau, K. Aubry, A. Delisle, Comparing the results of eight methods used to evaluate risk factors associated with musculoskeletal disorders, International Journal of Industrial Ergonomics. 42(5) (2012) 478-488.

[18] S. Khosrawi, A. Rahimi, B. Vahdatpour, F. D. Skouie, O. Mashrabi, Work-related musculoskeletal disorders among cardiologist, Research Journal of Biological Sciences. 6(4) (2011)170-174.

[19] M. Mirmohamadi, J. N. Seraji, J. Shahtaheri, M. Lahmi, M. Ghasemkhani, Evaluation of risk factors causing musculoskeletal disorders using QEC method in a furniture producing unite," Iranian Journal of Public Health. 33(2) (2004) 24-27.

[20] A. D. Nimbarte, Risk of neck musculoskeletal disorders among males and females in lifting exertions, International Journal of Industrial Ergonomics. (2013) 1-7. 